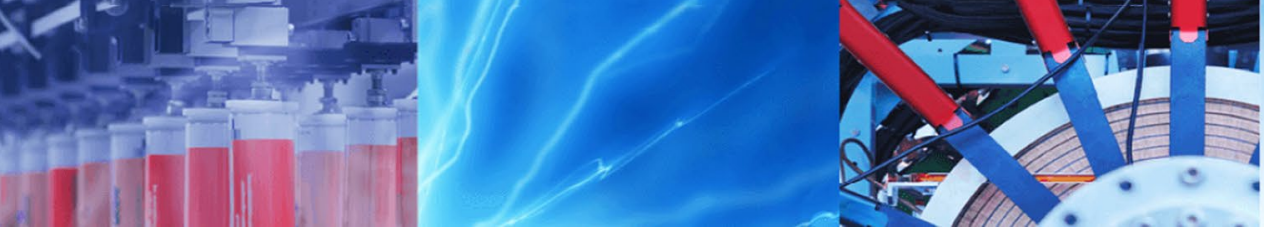

Research Article

\title{
Catalytic microwave synthesis of biphenyl urea over mesoporous $\mathrm{ZrO}_{2}-\mathrm{Al}_{2} \mathrm{O}_{3}$
}

\author{
Reena Saritha Serrao ${ }^{1,2} \cdot$ S. Z. Mohamed Shamshuddin ${ }^{1,2} \cdot$ T. E. Mohan Kumar ${ }^{1,2} \cdot$ H. M. Mandara ${ }^{2}$
}

Received: 7 April 2020 / Accepted: 15 May 2020 / Published online: 20 May 2020

(c) Springer Nature Switzerland AG 2020

\begin{abstract}
Solid acids such as $\mathrm{ZrO}_{2}, \mathrm{Al}_{2} \mathrm{O}_{3}$ and $\mathrm{ZrO}_{2}-\mathrm{Al}_{2} \mathrm{O}_{3}$ were prepared and analyzed for their physico-chemical properties like surface acidity and acid site distribution by $\mathrm{NH}_{3}$-TPD, crystalline nature by powder XRD, functionality by FT-IR, morphology by TEM and elemental analysis by ICP-OES methods. These solid acids were used as catalysts in the solvent free synthesis of biphenyl urea using microwave irradiation technique starting from aniline and dimethyl carbonate. Surface acidity and the phase of the solid acid were found to have a significant role in the synthesis of biphenyl urea. Up to (98\%) yield of biphenyl urea with $100 \%$ selectivity was obtained in just $12 \mathrm{~min}$. The activity of $\mathrm{ZrO}_{2}-\mathrm{Al}_{2} \mathrm{O}_{3}$ was compared with $\mathrm{Mo}(\mathrm{VI}) / \mathrm{ZrO}_{2}$ which is a solid super acid. For comparison, the reactions were also carried out by using conventional heating method. Kinetic studies were carried out to determine energy of activation of the solid acids. These solid acid catalysts were found to be reactivable and reusable when used for up to six reaction cycles.
\end{abstract}

Keywords Microwave $\cdot$ Modified $\mathrm{ZrO}_{2} \cdot$ Mesoporous $\mathrm{ZrO}_{2}-\mathrm{Al}_{2} \mathrm{O}_{3} \cdot$ Solid acids

\section{Introduction}

Metal oxide, especially zirconia based solid acid catalysts have played a vital role as heterogenous catalysts in many industrially important organic transformations [1-3]. It is reported that the mixed oxide of zirconia with alumina (i.e., $\mathrm{ZrO}_{2}-\mathrm{Al}_{2} \mathrm{O}_{3}$ ) possess higher acidic character than either pure zirconia or pure alumina. i.e., acidity can be increased by incorporating alumina into zirconia ${ }^{4}$. Such mixed oxide form has been used in organic reactions such as esterification, transesterification, condensation, acetylation, etc. $[5,6]$.

$\mathrm{N}, \mathrm{N}^{\prime}$-diaryl urea are a class of organic compounds which have significant roles in biological and medical applications [7]. These compounds are mainly used in agrochemical, dye, resin, fibre and pharmaceutical industries [8]. Especially, biphenyl urea (BPU) is studied extensively because of its importance in industries and academics for the production of carbamates and isocyanates [9]. Normally, BPU and its derivatives are synthesized by using toxic and environmental unfriendly reagents like phosgene, CO, formamides, etc. [10]. Generally, it is prepare by phosgenation route which has a major drawback such as corrosion. Another method is by the reaction between a cyclic carbonic ester with an amine. This method is expensive and is not reliable for industrial level production [11]. The synthesis of BPU and its derivatives over AIPOs, supported $\mathrm{MnO}$ catalysts is also reported [7-12]. These methods involve either toxic reagents or consuming reaction times or tedious routes.

In the recent years, high speed microwave irradiation has been used for various applications such as organic synthesis, where the reactions are accelerated by the absorption of microwave energy by the reactant molecules [13, 14]. Microwave-assisted reactions are energy-efficient and quick to synthesize fine chemicals [15]. The literature

S. Z. Mohamed Shamshuddin, mohamed.shamshuddin@gmail.com | ${ }^{1}$ Research and Development Center, Bharathiar University, Coimbatore, India. ${ }^{2}$ Chemistry Research Laboratory, HMS Institute of Technology, NH-4, Kyathsandra, Tumakuru, Karnataka, India. 
survey revealed that microwave irradiated heating method could be effectively used in industrially important reactions such as transesterification, alkylation, acetylation, coupling, etc. [16-19].

In this article an effort to synthesize biphenyl urea (BPU) over solid acids like $\mathrm{ZrO}_{2}, \mathrm{Al}_{2} \mathrm{O}_{3}$ and $\mathrm{ZrO}_{2}-\mathrm{Al}_{2} \mathrm{O}_{3}$ under microwave irradiation condition is made. The solid acids were prepared and analyzed for their surface acidic properties, crystalinity, functionality, morphology and elemental analysis. Optimization of reaction conditions was studied by altering the reaction parameters such as nature of solid acid catalyst, molar ratio of the reactants, amount of the catalyst, reaction temperature and time period. Kinetic studies were carried out to determine energy of activation of the solid acids. A study on the reactivation and reusability of these solid acid catalysts was also carried out.

\section{Experimental}

\subsection{Materials}

Zirconyl nitrate, aluminium nitrate nonahydrate, ammonium molybdate, aniline and dimethyl carbonate were supplied by M/S SD Fine Chemicals India Ltd.

\subsection{Preparation of $\mathrm{ZrO}_{2}$ and $\mathrm{Al}_{2} \mathrm{O}_{3}$}

$\mathrm{ZrO}_{2}$ was prepared by precipitation technique $[4,5]$ by using $20 \mathrm{~g}$ of zirconyl nitrate dissolved in $100 \mathrm{~mL}$ of deionised water to obtain a solution. This solution was heated at $353 \mathrm{~K}$ for $10 \mathrm{~min}$ and precipitation was carried out using ammonia solution (1:1) with stirring. Thus obtained precipitate of $\mathrm{Zr}(\mathrm{OH})_{4}$ was filtered using a Buchner funnel, washed with deionized water, dried in hot air oven at $393 \mathrm{~K}$ for $12 \mathrm{~h}$, finely powdered and calcined at $823 \mathrm{~K}$ for $5 \mathrm{~h}$ in a furnace. Similarly, pure $\mathrm{Al}_{2} \mathrm{O}_{3}$ was prepared by using aluminum nitrate.

\subsection{Preparation of $\mathrm{ZrO}_{2}-\mathrm{Al}_{2} \mathrm{O}_{3}$}

$\mathrm{ZrO}_{2}-\mathrm{Al}_{2} \mathrm{O}_{3}$ consisting of $10 \%, 20 \%$ and $40 \% \mathrm{ZrO}_{2}$ were prepared by using co-precipitation method. Typically, to prepare $40 \% \mathrm{ZrO}_{2}-\mathrm{Al}_{2} \mathrm{O}_{3}, 10.0 \mathrm{~g}$ of aluminum nitrate nonahydrate and $2.05 \mathrm{~g}$ of zirconyl nitrate were dissolved in $300 \mathrm{~mL}$ deionized water and heated to $353 \mathrm{~K}$ for $1 \mathrm{~h}$. The hot solution was filtered for remove any undissolved impurities. The solution was cooled to room temperature and precipitated using 1:1 ammonia solution. The resulting precipitate was filtered using a Buchner funnel, washed with deionized water, dried in hot air oven at $393 \mathrm{~K}$ for $12 \mathrm{~h}$, finely powdered and calcined at $823 \mathrm{~K}$ for $5 \mathrm{~h}$ in a furnace. Similarly, $\mathrm{ZrO}_{2}-\mathrm{Al}_{2} \mathrm{O}_{3}$ consisting of $10 \%$ and $20 \%$ were prepared.

\subsection{Preparation of $5 \% \mathrm{Mo}(\mathrm{VI}) / \mathrm{ZrO}_{2}$}

$4.5 \mathrm{~g}$ of zirconyl nitrate and $0.16 \mathrm{~g}$ of ammonium molybdate were taken in a china dish and made into a paste. The paste was then dried at $393 \mathrm{~K}$ for $12 \mathrm{~h}$ in a hot air oven and the obtained solid was finely powdered. The powder was calcinated in a furnace for $5 \mathrm{~h}$ at $823 \mathrm{~K}$.

The calcined solid acids such as $\mathrm{ZrO}_{2}, \mathrm{Al}_{2} \mathrm{O}_{3}, \mathrm{ZrO}_{2}-\mathrm{Al}_{2} \mathrm{O}_{3}$ (consisting of $10 \%, 20 \%, 40 \% \mathrm{ZrO}_{2}$ ) and $5 \% \mathrm{Mo}(\mathrm{VI}) / \mathrm{ZrO}_{2}$ were abbreviated as $Z, A, 10 Z A, 20 Z A, 40 Z A$ and $M Z$ respectively.

\subsection{Characterization of solid acids}

The solid acids such as Z, A, ZA and MZ were analyzed for their surface acidity by $\mathrm{NH}_{3}$-TPD (Mayura TPD unit), crystalinity by Powder X-ray diffraction (Philips X'Pert diffractometer using CuKa), functionality by FT-IR (Nicolet) technique, morphology by TEM (JEOL 2010) and ICP-OES (i-CAP 6000) method was used for elemental analysis.

\subsection{Catalytic activity of solid acids (in the microwave irradiated synthesis of biphenyl urea)}

Biphenyl urea (Scheme 1) was synthesized by taking a mixture of aniline $(10 \mathrm{mmol})$, dimethyl carbonate $(20 \mathrm{mmol})$ and $0.1 \mathrm{~g}$ of the solid acid catalyst ( $Z$ or $A$ or $Z A$ or $M Z$ ) in a microwave reactor vessel. The total volume of the reaction mixture was maintained always at $20 \mathrm{~mL}$. The reaction mixture was heated in a microwave reactor (Labmatrix India Pvt Ltd) fitted with a reflux condenser at $383 \mathrm{~K}$ for a fixed period of time with stirring. The maximum irradiation power of $1100 \mathrm{~W}$ was used in the initial $1.0 \mathrm{~min}$ of the reaction to obtain the desired reaction temperature, and then, variable power of 500-650 W was used. After the stipulated reaction time the reactor vessel was taken out from the microwave reactor an cooled to room temperature
Scheme 1 Synthesis of BPU from aniline and dimethyl carbonate over a solid acid catalyst

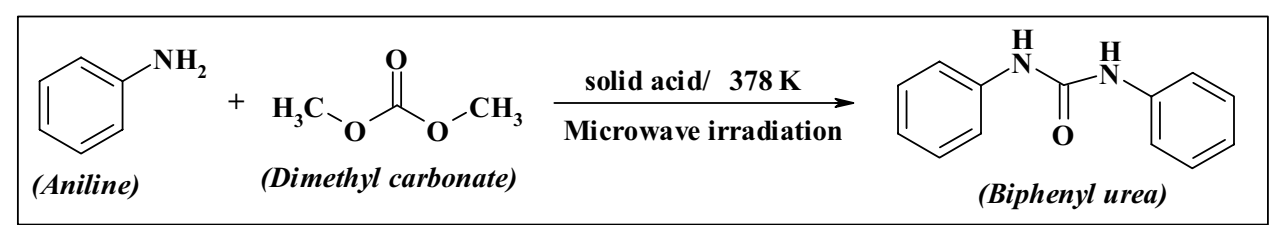


to which $10 \mathrm{~mL}$ of hot ethanol was added to dissolve the solid product. The solid acid catalyst was separated from the reaction mixture by filtration. The organic layer left behind was kept aside for crystallization of biphenyl urea (BPU). The product consisting of BPU was analyzed for its melting point (Anamatrix), ${ }^{1} \mathrm{H}$ NMR spectroscopy (Bruker, $400 \mathrm{MHz}$ ) and LC-MS (Varian).

Further, reactions were carried out to optimize the conditions like nature of the solid acid catalyst, weight of catalyst, reaction temperature and reaction time.

The kinetic studies were conducted in a temperature range from $353 \mathrm{~K}$ to $393 \mathrm{~K}$. The reactions were carried out by following the procedure as mentioned in the earlier paragraph, by varying the amount of catalysts $(0.05-0.2 \mathrm{~g})$ and reaction time $(2.0-20.0 \mathrm{~min})$.

The conversion (\%), selectivity (\%) and yield (\%) of products was calculated by using the following equations:

Conversion $(\%)$ aniline $=100-100 \times \frac{[\text { Aniline }]}{[\text { Aniline }+ \text { DMC }]}$

Selectivity $(\%) \mathrm{BPU}=100 \times \frac{[\mathrm{BPU}]}{[\mathrm{BPU}]+[\mathrm{N}-\text { methylaniline }]}$

Yield $(\%)$ BPU $=100 \times \frac{\text { Experimental yield of BPU }}{\text { Theoritical yield of BPU }}$

\subsection{Reactivation and reusability of solid acids}

The used solid acid was washed thoroughly with acetone, dried in an oven and finally calcined for $1 \mathrm{~h}$ at $823 \mathrm{~K}$. Such reactivated solid acid was reused in the next consecutive cycle of BPU synthesis.

\section{Results and discussion}

\subsection{Acidity of the solid acids}

The data pertaining to the total surface acidity (TSA) and acid site distribution of solid acid catalysts determined by $\mathrm{NH}_{3}$-TPD method are shown in Table 1.

Pure oxides such as zirconia and alumina were least acidic compared to their mixed oxide forms. However, mixed oxides were found to be more acidic than their individual forms. Increase in the acidity of mixed oxides can be due to the imbalance of positive charge when $\mathrm{Al}^{3+}$ is inserted into $\mathrm{Zr}^{4+}$ lattice, which creates Lewis acid sites [20]. Interestingly, all the solids used for the present work consisted of only 'weak and moderate' acid sites. MZ samples consisted of 'moderate and strong' sites [6].
Table 1 Acidic properties of solid acids used for the present work

\begin{tabular}{lllll}
\hline Solid acid & \multicolumn{2}{l}{ Acid site distribution $(\mathrm{mmol} / \mathrm{g})$} & \multirow{2}{*}{ TSA (mmol $/ \mathrm{g})$} \\
\cline { 2 - 4 } & Weak & Moderate & Strong & \\
\hline Z & 0.04 & 0.35 & - & 0.39 \\
$\mathrm{~A}$ & 0.08 & 0.36 & - & 0.44 \\
$10 \mathrm{AZ}$ & 0.13 & 0.55 & - & 0.68 \\
$20 \mathrm{AZ}$ & 0.19 & 0.80 & - & 0.99 \\
$40 \mathrm{AZ}$ & 0.23 & 0.95 & - & 1.18 \\
$\mathrm{MZ}$ & - & 0.99 & 0.24 & 1.23 \\
\hline
\end{tabular}

\subsection{PXRD of solid acids}

The powder $X R D$ patterns of $Z, A, Z A$ and $M Z$ samples are presented in Fig. 1[A]. PXRD patterns of $Z$ and $A$ shows the characteristic reflections pertaining to monoclinic, tetragonal and rhombohedral phases respectively. Whereas, in case of $Z A$, reflections due to a mixture of tetragonal and rhombohedral phases could be seen. No reflections pertaining to monoclinic phase of zirconia were observed in ZA samples. When the PXRD patterns of 10ZA, 20ZA and $40 \mathrm{ZA}$ samples are observed, the intensity of peaks corresponding to tetragonal phase of zirconia increases gradually with an increase in the concentration of zirconia [21]. This is due to a relative decrease in the concentration of $\mathrm{Al}_{2} \mathrm{O}_{3}$ as well as due to inherently poor intensity of peaks related to $\mathrm{Al}_{2} \mathrm{O}_{3}$. In case of $40 \mathrm{ZA}$, no peaks corresponding to alumina are observed. i.e., peaks due to tetragonal zirconia are seen. This indicates that 40ZA consists of only tetragonal phase which is catalytically active. Interestingly no peaks corresponding to monoclinic $\mathrm{ZrO}_{2}$ are observed in the PXRD patterns of ZA samples. PXRD pattern of $M Z$ consisted of only tetragonal phase of zirconia and monoclinic phase is absent indicating the phase stabilization property of $\mathrm{Mo}(\mathrm{VI})$ ions (Fig. 1[B]).

Further, a correlation between the surface acidity, tetragonal phase and the catalytic activity of zirconia based solid acids could be observed. The solid acid $40 \mathrm{AZ}$ which contains tetragonal phase was found to be more acidic and more catalytically active in the acid catalyzed reaction between aniline and DMC leading to the formation BPU.

\subsection{FT-IR studies of solid acids}

Figure 2 represents FT-IR spectra of $Z, A$ and $Z A$. The presence of $\mathrm{Zr}-\mathrm{OH}$ (bending mode) and $\mathrm{Zr}$-O- $\mathrm{Zr}$ (stretching mode) are indicated by the bands at $\sim 1391 \mathrm{~cm}^{-1}$ and $\sim 1118 \mathrm{~cm}^{-1}$ respectively which indicate the presence of $\mathrm{ZrO}_{2}$ phases in all the solid acids used for the present work except for alumina. A broad band at $\sim 1600 \mathrm{~cm}^{-1}$ due to the vibrations of acidic $-\mathrm{OH}$ and another band 
Fig. 1 [A] PXRD patterns of solid acids: $\mathbf{a ~} \mathrm{Al}_{2} \mathrm{O}_{3}, \mathbf{b} \mathrm{ZrO}_{2}, \mathbf{c}$ $10 \mathrm{AZ} \mathbf{d} 20 \mathrm{AZ}$ and e 40AZ. [Rrhombohedral $\mathrm{Al}_{2} \mathrm{O}_{3}$, T-tetragonal $\mathrm{ZrO}_{2}$ ]. [B] PXRD pattern and FTIR spectra of MZ sample

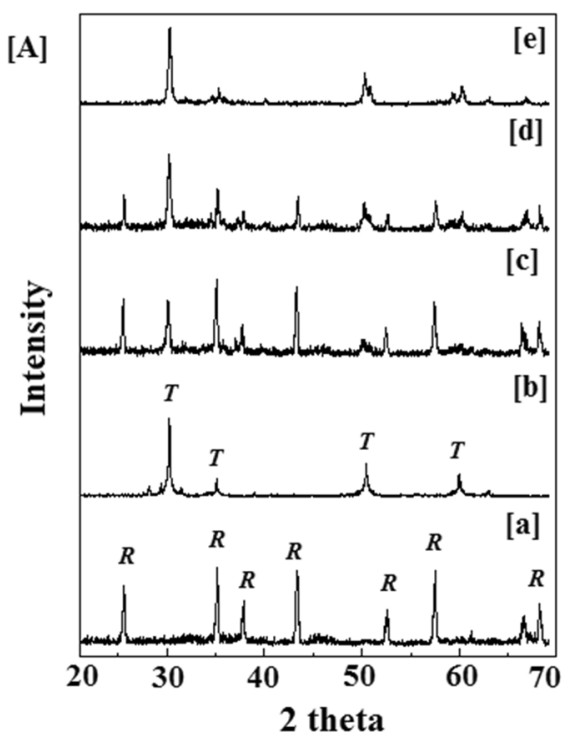

[B]

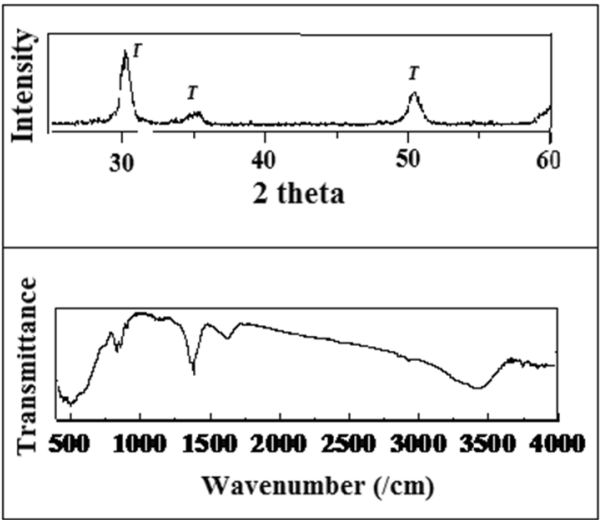

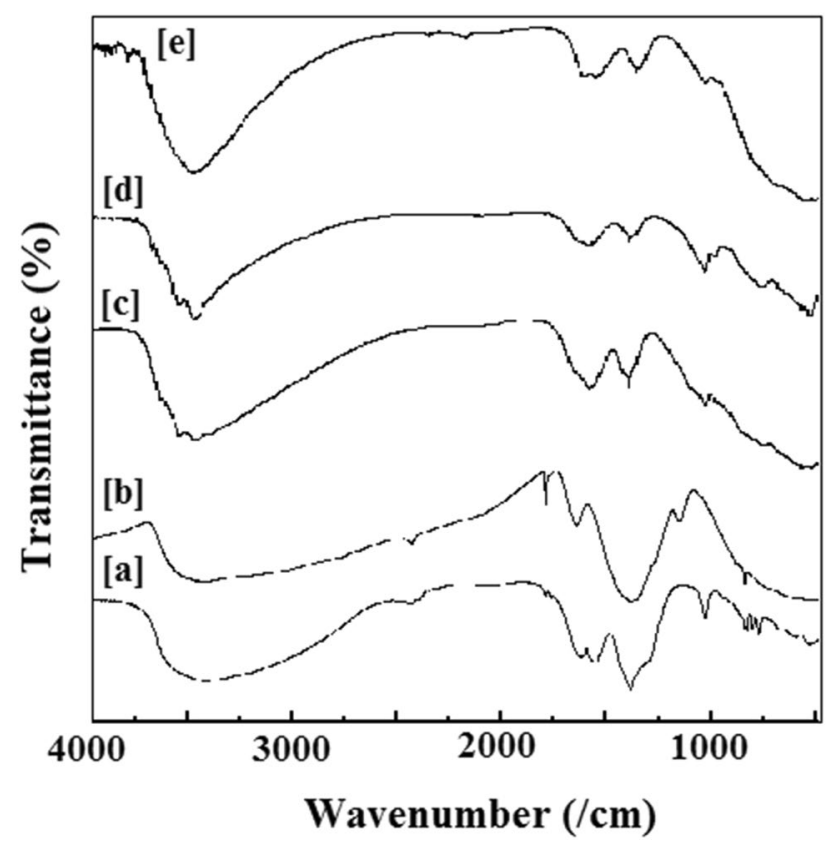

Fig. 2 FTIR spectra of solid acids: a $\mathrm{Al}_{2} \mathrm{O}_{3}$, b $\mathrm{ZrO}_{2}$, c $10 \mathrm{AZ}$ d $20 \mathrm{AZ}$ and e $40 A Z$

at $\sim 3400 \mathrm{~cm}^{-1}$ (stretching mode) with hydrogen bonding can also be observed. For the samples containing alumina, bands at $1050 \mathrm{~cm}^{-1}, 770 \mathrm{~cm}^{-1}$ and $690 \mathrm{~cm}^{-1}$ corresponding to O-Al vibrations could be seen [4].

\subsection{TEM studies}

TEM image of $40 \mathrm{ZrO}_{2}-\mathrm{Al}_{2} \mathrm{O}_{3}$ is shown in Fig. 3. The particle size of $40 \mathrm{AZ}$ was found to be in the range between $25-40 \mathrm{~nm}$ indicating that it is mesoporous in nature.

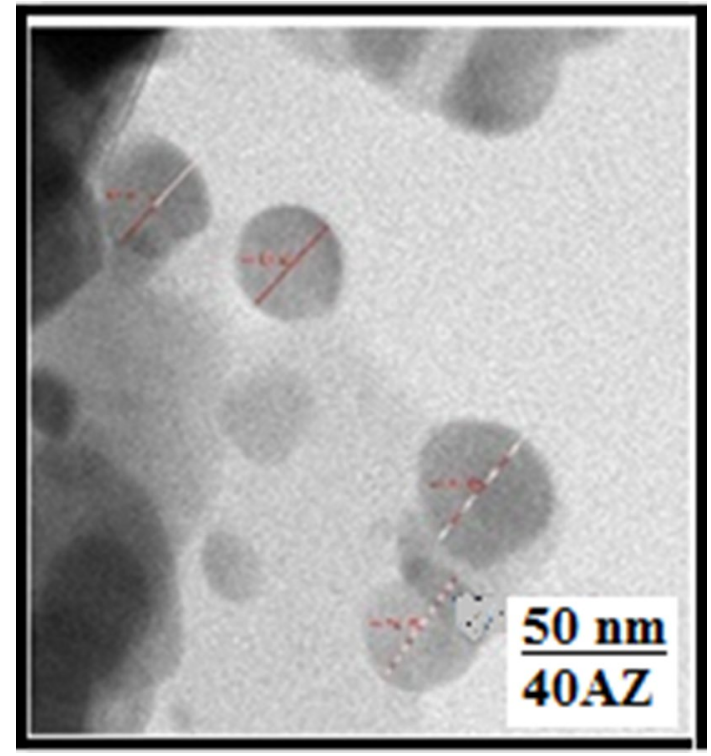

Fig. 3 TEM image of $40 A Z$

\subsection{ICP-OES studies}

The elemental analysis carried out for ZA solid acids via ICP-OES indicates the presence of $10.2 \%, 20.6 \%$ and $40.9 \%$ of zirconia in 10ZA, 20ZA and 40ZA samples respectively. $\mathrm{MZ}$ sample consisted of $4.8 \% \mathrm{Mo}(\mathrm{VI})$.

\subsection{Catalytic activity studies of solid acids (in microwave-assisted BPU synthesis)}

The microwave-assisted reactions between aniline and DMC were carried out over the solid acids $(Z, A, Z A$, $M Z$ ) used for the present study (Table 2). A correlation 
Table 2 Comparative catalytic activity of Z, A, ZA and MZ in microwave-assisted BPU synthesis

\begin{tabular}{llll}
\hline Solid acid & $\begin{array}{l}\text { Conversion of } \\
\text { aniline (\%) }\end{array}$ & $\begin{array}{l}\text { Selectivity } \\
\text { towards BPU } \\
(\%)\end{array}$ & $\begin{array}{l}\text { Selectivity towards } \\
\text { by-products (\%) }\end{array}$ \\
\hline Z & 46 & 100 & 00 \\
A & 49 & 100 & 00 \\
10ZA & 61 & 100 & 00 \\
20ZA & 77 & 100 & 00 \\
$40 Z A$ & 98 & 100 & 00 \\
MZ & 100 & 77 & 23
\end{tabular}

[Reaction conditions Molar ratio of aniline: $\mathrm{DMC}=1: 3$, weight of solid acid $=0.1 \mathrm{~g}$, temperature $=383 \mathrm{~K}$, time $=12 \mathrm{~min}]$

between the acidic properties and the catalytic activity was observed. Zirconia and alumina having lowest acidity showed least activity in the reaction followed by other solid acids such as MZ and ZA. Among ZA samples, 40ZA showed highest conversion of aniline when compared to either 10ZA or 20ZA which can be due to its highest acidity and possess catalytically active tetragonal phase of zirconia. Further, it is reported that rhombohedral alumina is less active in acid catalysed reactions [22]. Hence, 10ZA and 20ZA consisting of rhombohedral alumina are less active when compared to 40ZA.

However, over MZ in addition to BPU and N-methyl aniline was also formed as the by-product. The formation of by-product can be attributed to the presence of 'strong' acid sites in MZ. This infers that the formation of BPU requires 'weak and moderate' sites. Even though $M Z$ shows $100 \%$ conversion of aniline, it is less selective towards the formation of BPU (1,3-biphenyl urea). Therefore, for further optimization work, 40ZA was chosen because it produced reasonably good yield of BPU (98\%) with 100\% selectivity.

\subsection{Effect of mole ratio of the reactants on the conversion (\%) of aniline}

The reactions were conducted with molar ratios of aniline: $\mathrm{DMC}=1: 1,1: 2,1: 3,1: 4$ and $1: 5$ in presence of $0.05 \mathrm{~g}$ of $40 \mathrm{ZA}$ solid acid under microwave irradiation and the results are presented as Fig. 4. With an increase in the molar ratio of the reactants, the conversion (\%) of aniline also increased from 42 to 98 . This is because the reaction between aniline with $D M C$ is an equilibrium chemical reaction and since the position of equilibrium controls the amount of BPU formed, the use of an excess of DMC increases the conversion (\%) of aniline. However, the increase in the conversion was up to a molar ratio of 1:3 but becomes almost stable beyond this molar ratio. Therefore, for further optimization studies molar ratio of aniline: $\mathrm{DMC}=1: 3$ was found to be suitable.

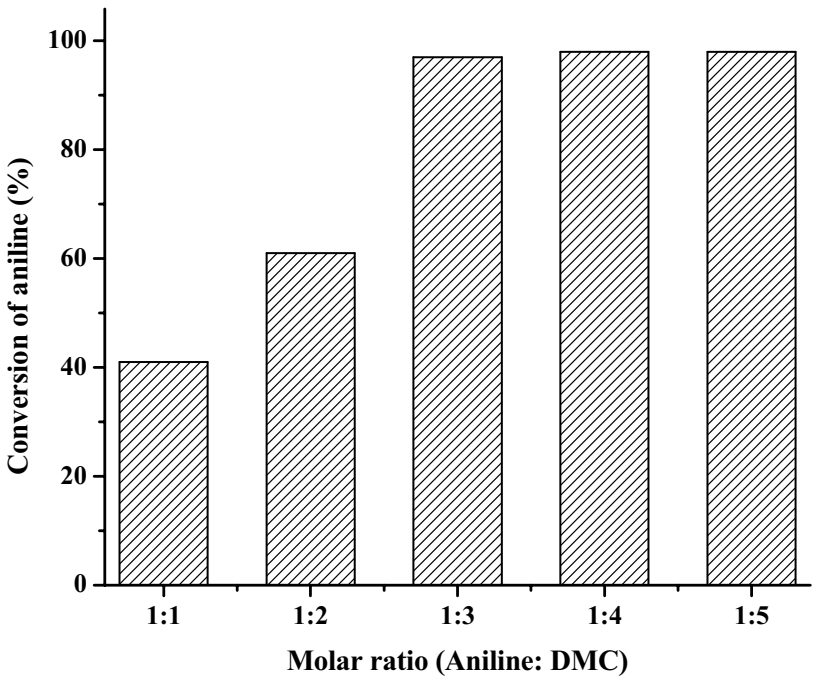

Fig. 4 Effect of molar ratio of aniline: DMC on the conversion (\%) of aniline. [Reaction conditions Amount of $40 Z A$ solid acid $=0.1 \mathrm{~g}$, temperature $=383 \mathrm{~K}$, time $=12 \mathrm{~min}]$

\subsection{Effect of reaction time on the conversion (\%) of aniline}

The reactions between aniline and DMC were conducted at different reaction times ranging from $2 \mathrm{~min}$ to $20 \mathrm{~min}$ and the results are presented in Fig. 5. The conversion (\%) of aniline increased with an increase in the reaction time until $12 \mathrm{~min}$ and reached $98 \%$. Further increase in the reaction time beyond $12 \mathrm{~min}$ did not show any reasonable change in the conversion (\%) of aniline indicating that the reaction attains equilibrium when the reaction

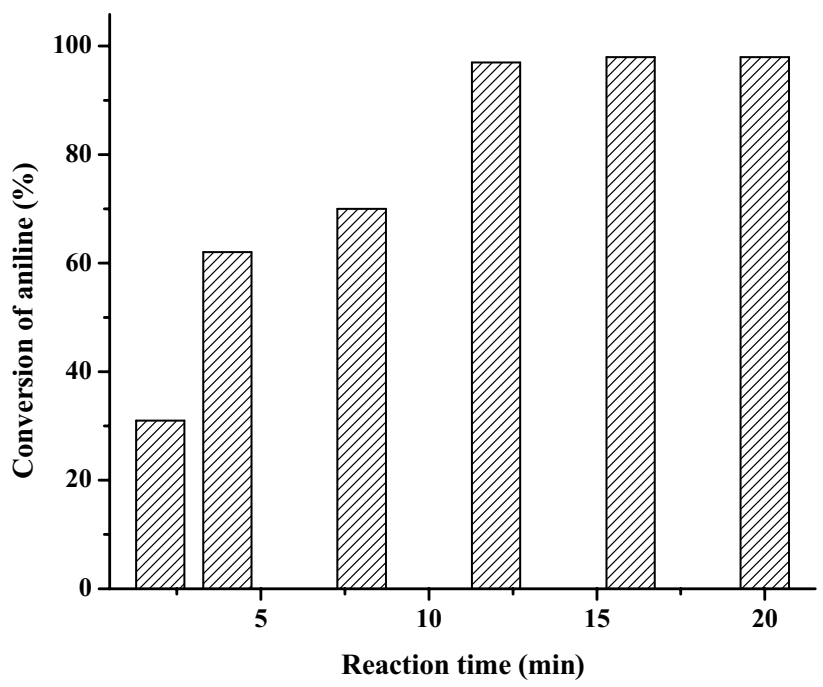

Fig. 5 Effect of reaction time period on the conversion (\%) of aniline. [Reaction conditions Molar ratio of aniline: $\mathrm{DMC}=1: 3$, weight of $40 Z$ A solid acid $=0.1 \mathrm{~g}$, temperature $=383 \mathrm{~K}$ ] 
time reaches $12 \mathrm{~min}$. Therefore, $12 \mathrm{~min}$ was selected as the optimum reaction time.

\subsection{Effect of reaction temperature on the conversion (\%) of aniline}

The reaction temperature was varied in the range from $353 \mathrm{~K}$ to $393 \mathrm{~K}$ and its effect on the conversion of aniline over 40ZA solid acid and the results are given Fig. 6 . The conversion (\%) of aniline was found to get increased with an increase in the temperature (up to $383 \mathrm{~K}$ ) because increasing the temperature apparently favors the acceleration of the forward reaction. Beyond $383 \mathrm{~K}$, though the conversion of aniline increased slightly, the selectivity towards the desired product BPU was found to decrease with the formation of the expected by-product such as $\mathrm{N}$-methyl aniline. This indicates that the formation of byproduct is not only influenced by the presence of strong acid sites on the catalyst ( $M Z$ catalyst) but also influenced by elevated reaction temperature which involves higher energy. Therefore, $383 \mathrm{~K}$ was chosen as the optimum reaction temperature for the synthesis of BPU with $100 \%$ selectivity over 40ZA solid acid.

\subsection{Effect of amount of the catalyst on the conversion (\%) of aniline}

The effect of amount of solid acid catalyst on the conversion (\%) of aniline was studied by varying the catalyst weight from 0.05 to $0.2 \mathrm{~g}$ (Fig. 7). An increase in the amount of the catalyst resulted in an increase the conversion (\%) of aniline till $0.01 \mathrm{~g}$. Further increase in the

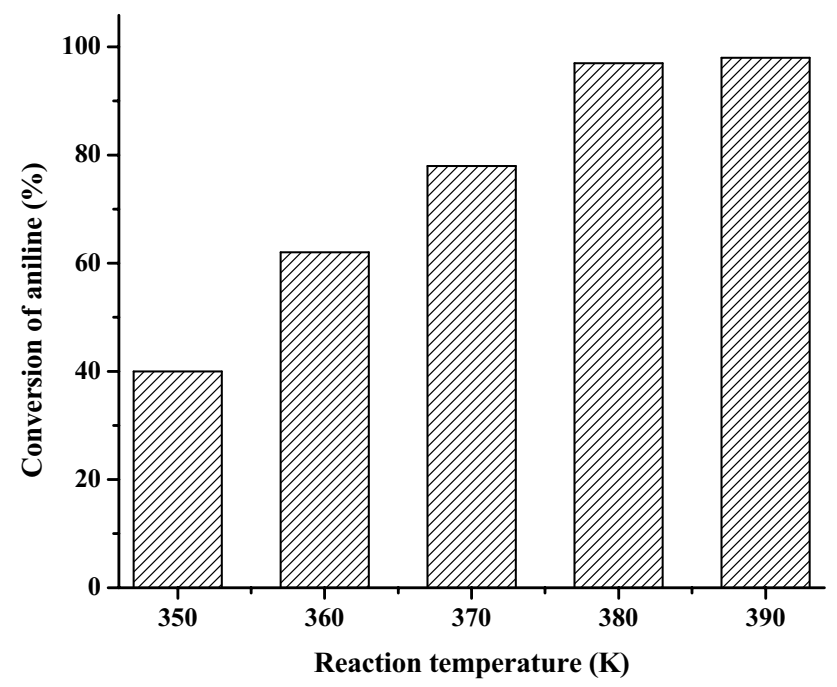

Fig. 6 Effect of reaction temperature on the conversion (\%) of aniline. [Reaction conditions Molar ratio of aniline: $D M C=1: 3$, weight of $40 \mathrm{ZA}$ solid acid $=0.1 \mathrm{~g}$, time $=12 \mathrm{~min}$ ]

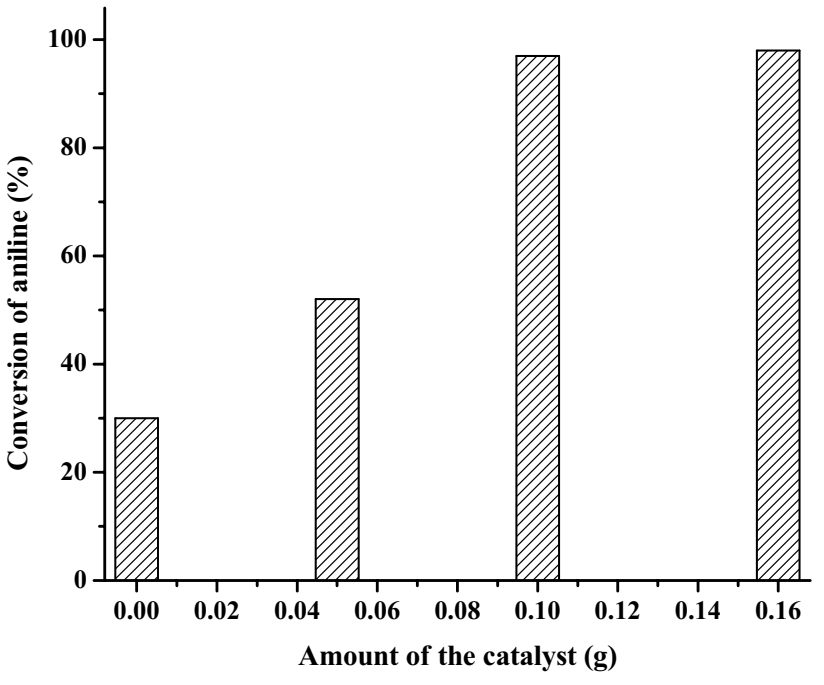

Fig. 7 Effect of amount of the solid acid catalyst on the conversion (\%) of aniline. [Reaction conditions Molar ratio of aniline: $\mathrm{DMC}=1: 3$, temperature $=383 \mathrm{~K}$, time $=12 \mathrm{~min}$ ]

amount of the catalyst did not show significant increase in the conversion (\%) of aniline.

\subsection{Effect of heating method (microwave $\mathrm{v} / \mathrm{s}$ conventional heating)}

The reactions between aniline and DMC were carried out by using two different heating methods such as microwave heating and conventional heating. The reactions were carried out over 40ZA solid acid under a set of reaction conditions and the results are shown in Table 3. The results clearly indicate that the microwave heating method is faster and facile when compared to conventional heating method.

In case of conventional heating, the reaction proceeded exceptionally slow since first heat is imparted to the reactants by transferring through the walls of the reaction vessel by making it a very slow as well as an inefficient method regarding transportation of energy into the reacting system is concerned. But, microwave heating was found to be superior with highest conversion (\%) of aniline ( twofold) in 12 min as compared to conventional

Table 3 Comparison between methods of heating with respect to the conversion (\%) of aniline

\begin{tabular}{lll}
\hline Heating method & Reaction time (min) & $\begin{array}{l}\text { Conversion } \\
\text { of aniline } \\
(\%)\end{array}$ \\
\hline Microwave & 12 & 98 \\
Conventional & 12 & 41 \\
Conventional & 80 & 84 \\
\hline
\end{tabular}


method. Further, up to $84 \%$ conversion of aniline was obtained when the reactions were carried out for $100 \mathrm{~min}$ under conventional heating method. Besides, the application of microwave energy is an expressway with higher reaction rates, reduced reaction times in managing and initiating the reaction towards equilibrium compared to conventional thermal radiation [14].

\subsection{Synthesis of various BPU derivatives over 40ZA}

The activity of 40ZA which showed excellent activity in the synthesis of BPU was further evaluated in the synthesis of BPU derivatives. The reactions were carried out with substituted anilines with DMC at $383 \mathrm{~K}$ for $12 \mathrm{~min}$. The yield (\%) of the BPU products are recorded in the Table 4 and the spectral data of the obtained BPU derivatives are given in the Table 5. When secondary substituted anilines were used in the reaction, the conversion of aniline is very low.
Whereas primary substituted anilines, when employed in a reaction, up to $90 \%$ yield of desired BPU derivatives was obtained.

\subsection{Kinetic studies}

The kinetic studies were conducted to compare the catalytic activity of heterogeneous solid acids (40AZ and MZ). Proceeding towards kinetic examination, experiments were performed to establish the mass and heat transfer limitations. Experiments were also conducted with different stirring rates for the reaction mixture. It was observed that the conversion (\%) aniline was independent of stirring rates. Not much change the conversion (\%) aniline was noticed. It may be assumed that any external resistance to its transfer from bulk liquid phase to the external surface is absent [23].
Table 4 Microwave irradiated synthesis of BPU derivatives over 40ZA

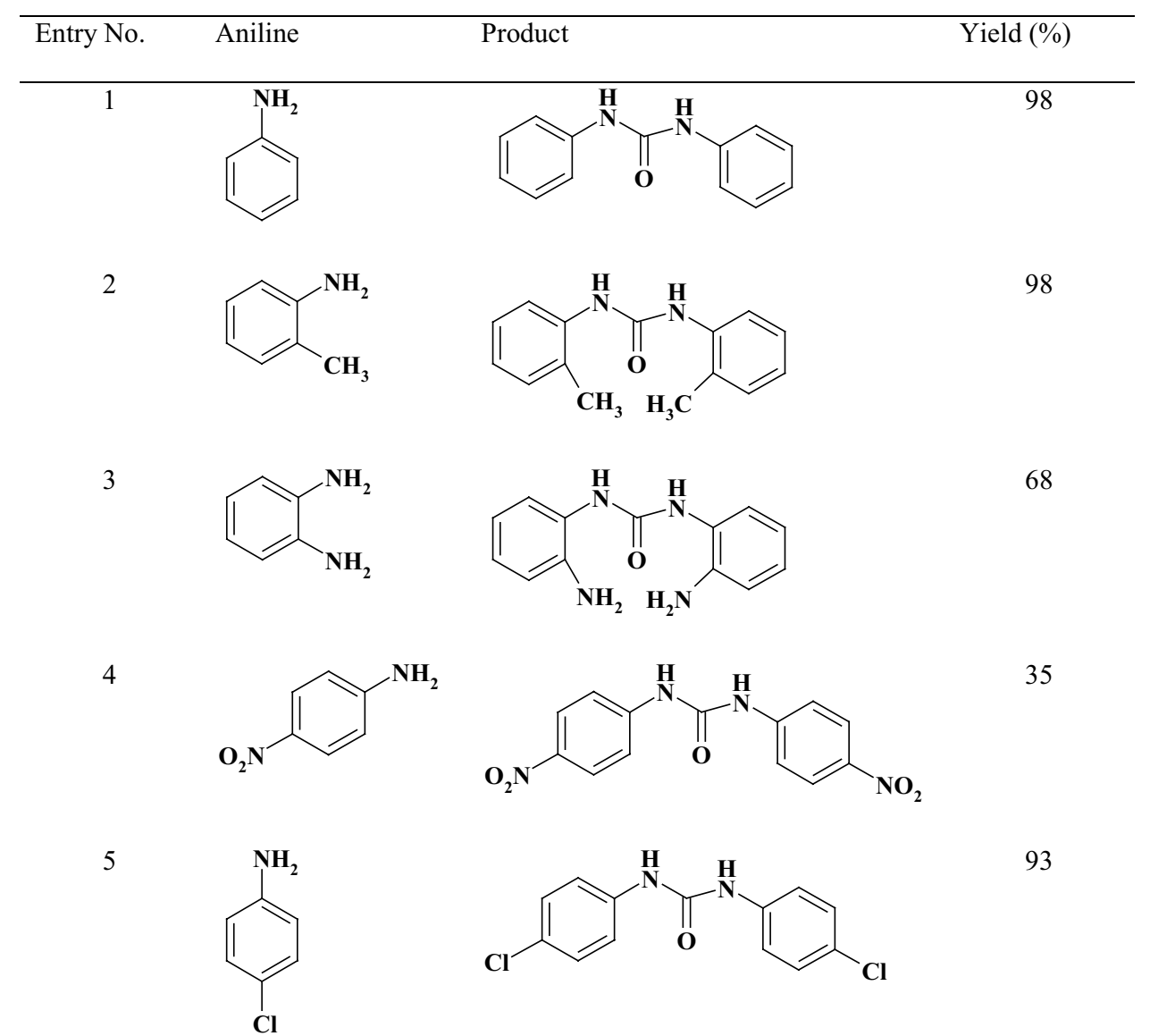

[Reaction conditions: Molar ratio of aniline: $\mathrm{DMC}=1: 3$, weight of solid acid $=0.1 \mathrm{~g}$ of 40ZA, temperature $=383 \mathrm{~K}$, time $=12 \mathrm{~min}]$.

[Reaction condi tions: Molar rat io of aniline: $\mathrm{DMC}=1: 3$, weight of solid acid $=0.1 \mathrm{~g}$ of $40 \mathrm{ZA}$, temperature $=383 \mathrm{~K}, \mathrm{t}$ ime $=12 \mathrm{~min}$ ] 
Table 5 Spectral data of BPU derivatives (Refer to Table 4)

\begin{tabular}{|c|c|c|}
\hline Entry No. & Product & Spectral data \\
\hline 1 & 1,3-biphenyl urea & $\begin{array}{l}\text { White crystalline shiny solid, M.P } 239-241^{\circ} \mathrm{C}, \mathrm{IR}(\mathrm{KBr}) 3291 \mathrm{~cm}^{-1}(\mathrm{~N}-\mathrm{H}), 1635 \mathrm{~cm}^{-1}(\mathrm{C}=\mathrm{O}) .{ }^{1} \mathrm{HNMR} \\
\left(300 \mathrm{~Hz} \text {, DMSO), } \mathrm{iH}: 6.52-7.4(\mathrm{Ar}-\mathrm{H}, \mathrm{m}, 10 \mathrm{H}), 8.2(\mathrm{~N}-\mathrm{H}, \mathrm{s}, 2 \mathrm{H}) . \mathrm{Ms}: \mathrm{M}^{+}=213.2 .\right.\end{array}$ \\
\hline 2 & 1,3-dio-tolyl urea & $\begin{array}{l}\text { Pale yellow crystalline solid, M.P } 283-285^{\circ} \mathrm{C}, \mathrm{IR}(\mathrm{KBr}) 3307 \mathrm{~cm}^{-1}(\mathrm{~N}-\mathrm{H}), 2935 \mathrm{~cm}^{-1}(\mathrm{C}-\mathrm{H}) 1641 \mathrm{~cm}^{-1} \\
(\mathrm{C}=\mathrm{O}) .{ }^{1} \mathrm{HNMR}(300 \mathrm{~Hz} \text {, DMSO), i } \mathrm{H}: 6.92-7.79(\mathrm{Ar}-\mathrm{H}, \mathrm{m}, 8 \mathrm{H}), 8.24(\mathrm{~N}-\mathrm{H}, \mathrm{s}, 2 \mathrm{H}), 2.50(-\mathrm{CH} 3, \mathrm{~s}, 3 \mathrm{H}) . \\
\text { Ms: } \mathrm{M}^{+}=241 .\end{array}$ \\
\hline 3 & 1,3-bis(2-amino phenyl) urea & $\begin{array}{l}\text { Yellow crystalline compound, IR (KBr) } 3291 \mathrm{~cm}^{-1}(\mathrm{~N}-\mathrm{H}), 3347 \mathrm{~cm}^{-1} \text { and } 3169 \mathrm{~cm}^{-1}(-\mathrm{NH} 2) \text {, } \\
1629 \mathrm{~cm}^{-1}(\mathrm{C}=\mathrm{O}) .{ }^{1} \mathrm{HNMR}(300 \mathrm{~Hz}, \mathrm{DMSO}), \mathrm{iH}: 6.72-7.34(\mathrm{Ar}-\mathrm{H}, \mathrm{m}, 8 \mathrm{H}), 8.34(\mathrm{~N}-\mathrm{H}, \mathrm{s}, 2 \mathrm{H}) . \mathrm{Ms} \text { : } \\
\mathrm{M}^{+}=241\end{array}$ \\
\hline 4 & 1,3-bis(2-nitrophenyl) urea & $\begin{array}{l}\text { Yellow crystalline solid; M.P=235-237 }{ }^{\circ} \mathrm{C} \text {, IR }(\mathrm{KBr}) 3347 \mathrm{~cm}^{-1}(\mathrm{~N}-\mathrm{H}), 1328 \mathrm{~cm}^{-1}(\mathrm{~N}=\mathrm{O}) 1649 \mathrm{~cm}^{-1} \\
(\mathrm{C}=\mathrm{O}),{ }^{1} \mathrm{HNMR}(300 \mathrm{~Hz}, \mathrm{DMSO}), \mathrm{iH}: 6.92-7.59(\mathrm{Ar}-\mathrm{H}, \mathrm{m}, 8 \mathrm{H}), 8.54(\mathrm{~N}-\mathrm{H}, \mathrm{s}, 2 \mathrm{H}), \mathrm{Ms}: \mathrm{M}^{+}=303.2 .\end{array}$ \\
\hline 5 & 1,3-bis(4-chloro phenyl) urea & $\begin{array}{l}\text { White crystalline shiny solid; M.P => } 300^{\circ} \mathrm{C}, \mathrm{IR}(\mathrm{KBr}) 3297 \mathrm{~cm}^{-1}(\mathrm{~N}-\mathrm{H}), 1637 \mathrm{~cm}^{-1}(\mathrm{C}=\mathrm{O}), 877 \mathrm{~cm}^{-1} \\
(\mathrm{C}-\mathrm{Cl}){ }^{1} \mathrm{HNMR}(300 \mathrm{~Hz}, \mathrm{DMSO}), \mathrm{iH}: 7.32-7.51(\mathrm{Ar}-\mathrm{H}, \mathrm{m}, 8 \mathrm{H}), 8.85(\mathrm{~N}-\mathrm{H}, \mathrm{s}, 2 \mathrm{H}) . \mathrm{Ms}: \mathrm{M}^{+2}=283 .\end{array}$ \\
\hline
\end{tabular}

Graphs of $-\ln [1$-Yield of BPU] against reaction time discussed at different temperatures over $40 Z A$ and MZ catalysts and presented in Fig. 8. Order of reaction was found to be first-order because linearity was noticed among all the plots.

The first-order rate constants obtained from the slopes and activation energy (Ea) determined using Arrhenius equation is given in Table 6 .

$E a=2.303 R \log \left(\frac{k 2}{k 1}\right)\left[\frac{T 1 \times T 2}{T 2-T 1}\right]$

where $\mathrm{R}=$ gas constant, $\mathrm{k}_{1}=$ rate constant at temperature $\mathrm{T}_{1}$ and $\mathrm{k}_{2}=$ rate constant at temperature $\mathrm{T}_{2}$.

In this work, faster kinetics was noticed in the case of 40ZA catalyst with a shorter reaction time 12 min when compared to a solid super acid (MZ) towards the formation of the desired reaction product i.e., BPU. This suggests that 40ZA is a proficient-solid acid for the present work.

\subsection{Reusability of solid acids}

Reusability studies of solid acid catalysts such as 40ZA and $M Z$ was investigated in microwave-assisted reaction between aniline and DMC in a molar ratio of 1:3 at $383 \mathrm{~K}$ for $12 \mathrm{~min}$. After the first reaction cycle, the solid product was separated from the mixture by adding $10 \mathrm{ml}$ of hot ethanol followed by filtration. The used solid acid catalyst was washed with acetone to remove any adsorbed organic impurities from the surface of the catalyst, dried in an air oven at $493 \mathrm{~K}$ for $2 \mathrm{~h}$ and calcined at $823 \mathrm{~K}$ for $1 \mathrm{~h}$. Thus reactivated catalysts were reused in the next consecutive reaction cycle and six such reusability cycles were studied and the data are presented in the form of Fig. 9.

It was observed that 40ZA solid acid was more reusable with no significant loss in its catalytic activity. However, $\mathrm{MZ}$ solid acid was found to deactivate gradually during its
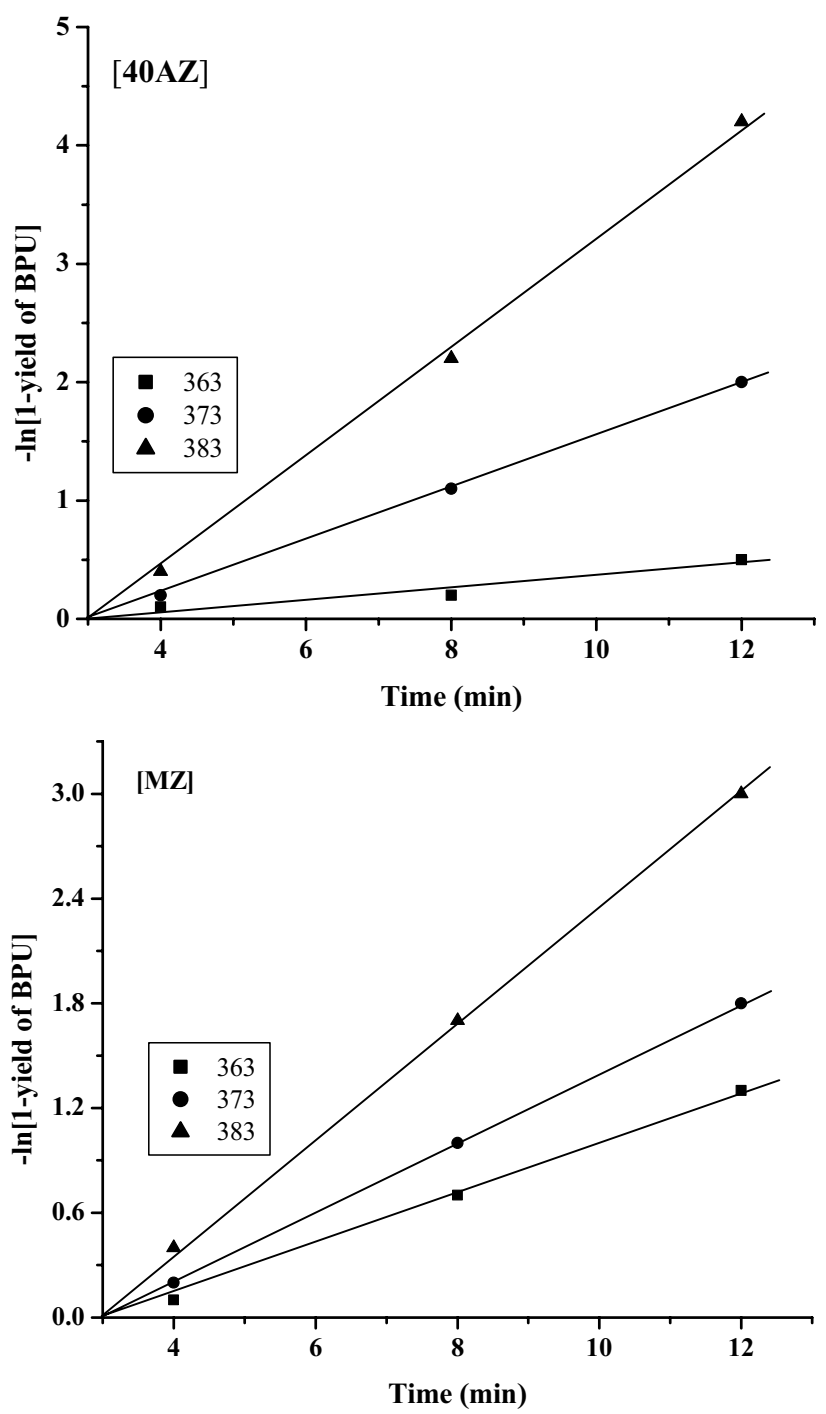

Fig. 8 The plot of first order rate constants for the reaction between aniline and DMC in the presence of 40ZA and MZ catalysts at $363 \mathrm{~K}, 373 \mathrm{~K}$ and $383 \mathrm{~K}$ 
Table 6 The energy of activation (Ea) \& rate constants (k) of 40ZA and $\mathrm{MZ}$ solid acid catalysts on yield (\%) of BPU

\begin{tabular}{llll}
\hline Solid acid catalyst & $\begin{array}{l}\text { Rate constant } \times 10^{-3} \mathrm{~min}^{-1} \\
\text { (Yield of BPU) }\end{array}$ & $\begin{array}{l}\text { Ea for the Yield } \\
\text { of BPU }(\mathrm{kJ} / \mathrm{mol})\end{array}$ \\
\cline { 2 - 3 } & $373 \mathrm{~K}$ & $383 \mathrm{~K}$ & \\
\hline $40 Z \mathrm{~A}$ & 1.36 & 2.29 & 42.0 \\
$\mathrm{MZ}$ & 1.22 & 2.89 & 66.2 \\
\hline
\end{tabular}

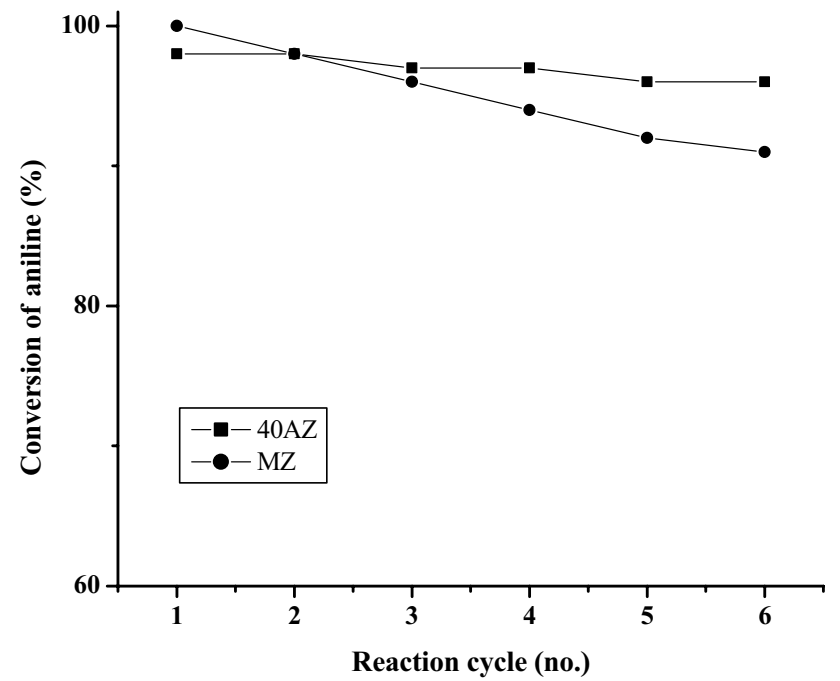

Fig. 9 Effect of reactivation of solid acid catalysts (40ZA and MZ) on the conversion (\%) of aniline

reuse in the consecutive reaction cycles which can be due to the strong adsorption of reactant or product molecules on the strong acid sites of $\mathrm{MZ}$.

\section{Conclusions}

Selective and fast synthesis of biphenyl urea was successfully carried out over zirconia-alumina based solid acids under microwave irradiation in a shorter period of time of just $12 \mathrm{~min}$. A correlation between the acidity of solid acid and the conversion of aniline was observed. The selectivity of BPU was influenced by the acid site distribution of solid acid catalyst. Zirconia-alumina which consisted of weak and moderate acid sites produced biphenyl urea with $100 \%$ selectivity. But $\mathrm{Mo}(\mathrm{VI}) / \mathrm{ZrO}_{2}$ was found to be less selective towards the formation of BPU because it also produced $\mathrm{N}$-methyl aniline as the by-product as it has 'strong' acid sites. $\mathrm{ZrO}_{2}-\mathrm{Al}_{2} \mathrm{O}_{3}$, especially mesoporous $40 \mathrm{ZrO}_{2}-\mathrm{Al}_{2} \mathrm{O}_{3}$ was ecofriendly and can be recycled for at least 6 reaction cycles without much deactivation. This solid acid can be successfully used as catalyst for the synthesis of BPU derivatives. Kinetic studies indicate that $40 \mathrm{ZrO}_{2}-\mathrm{Al}_{2} \mathrm{O}_{3}$ is more efficient with low Ea in the selective synthesis of biphenyl urea.

Acknowledgements The authors are gratefully for the part financial support given by VGST, GoK (GRD-375/2014-15) and grateful to the authorities of IISC and St. Joseph College, Bengaluru for GC-MS, TEM, ICP-OES and PXRD, analysis of catalysts.

\section{Compliance with ethical standards}

Conflict of interest On behalf of all authors, the corresponding author states that there is no conflict of interest.

\section{References}

1. Thomas JM, Thomas WJ (1997) Principles and practice of heterogeneous catalysis. VCH Wenhheim, New York

2. Tanabe K (1990) Solid acids and bases. Academic Press, New York

3. Hino M, Arata K (1988) Synthesis of solid superacid of tungsten oxide supported on zirconia and its catalytic action for reactions of butane and pentane. J Chem Soc, Chem Commun 18:1259

4. Thimmaraju N, Mohamed Shamshuddin SZ (2016) Simple but efficient synthesis of novel substituted benzimidazoles over $\mathrm{ZrO}_{2}-\mathrm{Al}_{2} \mathrm{O}_{3}$. Synth Commun 46(18):1537

5. Thimmaraju N, Mohamed Shamshuddin SZ (2016) Synthesis of 2,4,5-trisubstituted imidazoles, quinoxalines and 1,5-benzodiazepines over an eco-friendly and highly efficient $\mathrm{ZrO}_{2}-\mathrm{Al}_{2} \mathrm{O}_{3}$ catalyst. RSC Adv 6:60231

6. Yadav GD, Nair JJ (1999) Sulfated Zirconia and its modified versions as promising catalysts for industrial processes. Micropor Mesopor Mater 33:1

7. Nagaraju N, Kuriakose G (2002) A new catalyst for the synthesis of $\mathrm{N}, \mathrm{N}$-biphenylurea from aniline and dimethyl carbonate. Green Chem 4:269

8. Fernandes $H$, Bujacz A, Bujacz G, Jelen F, Jasinski M, Kachlicki P, Otlewski J, Sikorski MM, Jaskolski M (2009) Structural and functional aspects of PR-10 proteins. The FEBS J 276:1596

9. Srinivasan M, Nachiappan V, Rajasekharan R (2006) Potential application of urea-derived herbicides as cytokinins in plant tissue culture. J Biosci 31:599

10. March J (1985) Advanced organic chemistry. Wiley, New York

11. US Patent. 5902899. 1999

12. Rekha M, Nagaraju N (2013) Catalytic activity of manganese oxide supported on alumina in the synthesis of quinoxalines. Front Chem Sci Eng 7:415

13. Oliver Kappe $C$ (2002) Practical microwave synthesis for organic chemists: strategies, instruments. Curr Opin Chem Biol 6:314

14. Kappe CO (2004) Controlled microwave heating in modern organic synthesis. Angewnadte Chem 43:6250

15. Loupy A (2006) Microwaves in organic synthesis. Wiley-VCH, Weinheim

16. Venkatesha NJ, Bhat YS, Jai Prakash BS (2015) Re-usability of zeolites and modified clays for alkylation of cyclohexanol a contrast study. RSC Adv 5:69348

17. Venkatesha NJ, Bhat YS, Jai Prakash BS (2016) Dealuminated BEA zeolite for selective synthesis of five-membered cyclic acetal from glycerol under ambient conditions. RSC Adv 6:18824

18. Thimmaraju N, Mohamed Shamshuddin SZ (2015) Efficient microwave synthesis of novel aromatic esters catalyzed by zirconia and its modified forms: a kinetic study. RSC Adv 5:99517

19. Horikoshi S, Osawa A, Sakamoto S, Serpone N (2013) Control of Microwave-generated hot spots 6 . Generation of hot spots 
in dispersed catalyst particulates and factors that affect catalyzed organic syntheses in heterogeneous media. Appl Catal A 460-461:52

20. Pratap SR, Shamshuddin SZM (2018) Mesoporous $\mathrm{ZrO}_{2}-\mathrm{Al}_{2} \mathrm{O}_{3}$ (ZA) mixed metal oxide as an efficient and reusable catalyst for the liquid phase O-methoxymethylation reaction under solvent free conditions. J Por Mater 25(5):1365

21. D'Souza Joyce Q, Nagaraju N (2004) Vapour phase transesterification over solid acids for the synthesis of isoamyl salicylate. Indian J Chem Technol 11:401

22. Green DJ (1982) Critical microstructures for microcracking in Al2O3-ZrO2 composites. J Am Ceram Soc 65:610
23. Madon RJ, Boudart M (1982) Experimental criterion for the absence of artifacts in the measurement of rates of heterogeneous catalytic reactions. Ind Eng Chem Fundam 21:438

Publisher's Note Springer Nature remains neutral with regard to jurisdictional claims in published maps and institutional affiliations. 